\title{
Clinical utilization of ultrasonic piezoelectric bone surgery during osteotomy
}

\author{
Dong-Seok Sohn, Ph.D. \\ Section Editor of JKAOMS \\ Department of Dentistry and Oral and Maxillofacial Surgery, Catholic University Hospital of Daegu, Daegu, Korea
}

Various osteotomy instruments have been introduced in recent decades for use in the medical and dental fields. Among them, piezoelectric bone surgery (PBS) is an alternative to conventional rotary instruments that enables precise osteotomy with minimal soft-tissue damage during the healing peri$\operatorname{od}^{1}$. PBS can also reduce postoperative edema and ecchymosis compared to lateral osteotomy immediately after surgery.

PBS has also been widely used when performing osteotomy associated with ridge and sinus augmentation. Mucosal perforation during lateral window preparation can lead to severe complications such as poor bone regeneration, high implant failure, and sinusitis ${ }^{1}$. Because lower rate of mucosal perforation is reported in many studies, PBS is commonly used when crestal and lateral sinus elevation is performed. In addition, the lateral bony window created by the piezoelectric saw insert is repositioned precisely and also acts as an osteoinductive/osteoconductive substrate in the maxillary sinus in bone grafted/non-bone grafted sinus ${ }^{2}$. On the other hand, collagen barrier has no effect on bone regeneration. The use of the PBS makes it possible to create a lateral bony window without injury to the intraosseous artery because of microvibration and selective cutting ${ }^{3}$. High-speed surgical instruments can influence the probability of membrane perforation due to the limitations of anatomical structures of the sinus cavity. However, piezoelectric devices, with their pen grip,

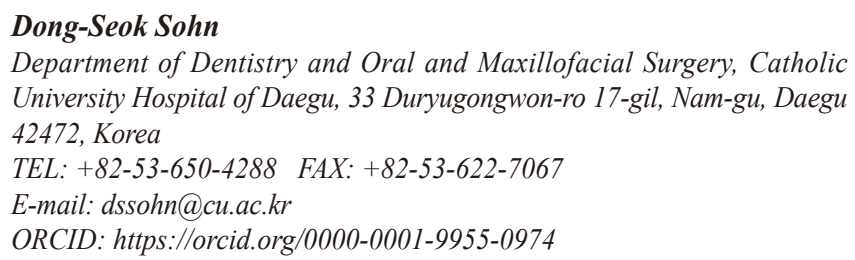

(c) This is an open-access article distributed under the terms of the Creative Commons Attribution Non-Commercial License (http://creativecommons.org/ licenses/by-nc/4.0/), which permits unrestricted non-commercial use, distribution, and reproduction in any medium, provided the original work is properly cited. Copyright (C) 2019 The Korean Association of Oral and Maxillofacial Surgeons. All rights reserved. can easily be used in the deep oral cavity.

Compared to conventional rotary instruments, PBS demonstrates higher bone cell viability and precise osteotomy. Therefore, PBS is considered a valid alternative to rotating burs when performing osteotomy for autogenous bone harvesting, removal of impacted teeth or cysts, distraction osteogenesis, other augmentation procedures, and cosmetic bony surgery. PBS is beneficial when immediate implant placement is performed because it provides bactericidal curettage in the extracted sockets with chronic inflammation. The benefits of PBS overcome its disadvantages such as slow cutting, and therefore its use is recommended for hard tissue dental and oral and maxillofacial procedures.

\section{Conflict of Interest}

No potential conflict of interest relevant to this article was reported.

\section{References}

1. Ghavimi MA, Nezafati S, Yazdani J, Pourlak T, Amini M, Pourlak T, et al. Comparison of edema and ecchymosis in rhinoplasty candidates after lateral nasal osteotomy using piezosurgery and external osteotomy. J Adv Pharm Technol Res 2018;9:73-9.

2. Kim JM, Sohn DS, Heo JU, Moon JW, Lee JH, Park IS. Benefit of the replaceable bony window in lateral maxillary sinus augmentation: clinical and histologic study. Implant Dent 2014;23:277-82.

3. Sohn DS, Moon JW, Lee HW, Choi BJ, Shin IH. Comparison of two piezoelectric cutting inserts for lateral bony window osteotomy: a retrospective study of 127 consecutive sites. Int J Oral Maxillofac Implants 2010;25:571-6.

How to cite this article: Sohn DS. Clinical utilization of ultrasonic piezoelectric bone surgery during osteotomy. J Korean Assoc Oral Maxillofac Surg 2019;45:173. https://doi.org/10.5125/jkaoms.2019.45.4.173 